\title{
Rejoinder to \\ Comparative economics and the mainstream by László Csaba
}

\section{Melissa Vergara-Fernández ${ }^{1}$}

I read Csaba’s tribute to János Kornai, "Comparative economics and the mainstream" with great interest and was impressed by his evident admiration for Kornai's work. Csaba's paper is a brief recount of Kornai's intellectual biography in which he highlights Kornai's major contribution of each decade. Throughout the paper, as the title might suggest, there is running commentary with respect to the relationship between Kornai's work and 'mainstream economics. The underlying question throughout the paper is why Kornai's work did not become more influential in the mainstream, if Kornai offered all the necessary ingredients for his work to become more recognised than it has actually been. Csaba's concern is that "Given his unparalleled embeddedness in the Western academic world ever since the mid-1960s... his highly original and equally unusually influential ideas have had a limited, if any, impact on mainstream economics, as taught in global economics programmes at $\mathrm{PhD}$ level" (p. 33). Csaba's narrative suggests that there was a kind of progression in Kornai's work that should have made him acceptable to the mainstream, but that, in the end, his "subject of analysis as well as the conditions under which the author formulated his academic interests... kept him within the confines of institutional economics" (p. 49). Due to space limitations I will only focus on two aspects that are important from the perspective of the philosophy of economics.

The first aspect is that which Csaba presents as Kornai's lifelong methodological choice and which Kornai himself called 'The system paradigm' (2000). This approach involves a holistic view of the object of study in which "the relevance of interdependencies among various elements and subfields" is highlighted. In the system paradigm, the institutional and legal framework by which the economic activity is made possible, as well as the sociological and ideological aspects, are constitutive of the analysis (Kornai, 1998). Csaba introduc-

\footnotetext{
${ }^{1}$ Erasmus University Rotterdam, Erasmus Institute for Philosophy and Economics (EIPE), Faculty of Philosophy, P.O Box 1738, 3000 DR Rotterdam, The Netherlands, vergarafernandez@fwb.eur.nl/melissa@mvergarafernandez.nl.
} 
es it as already present in Kornai's first work, Overcentralisation in Economic Administration, and one that would prevail throughout his work and become a distinctive feature of the field of comparative economics. Besides highlighting this holistic approach as one of the unique features of the book - and thereby of Kornai's achievement - Csaba also uses the opportunity to criticise mainstream economics for subscribing to another methodological approach. According to Csaba, Kornai's holistic approach to the macroeconomy, in which "everything depends on everything", is "a precondition for any partial analysis to make sense" (p. 35). Csaba thus criticises the partial analysis and comparative statics 'ruling in the mainstream' as nonsensical; "no individual element of the economy deserves meaningful scrutiny unless it is embedded in the structure which sets its workings in motion" (p. 35).

To be sure, Csaba's concern about how to proceed in order to understand economic phenomena is not new. A similar distinction has been drawn in economics between the Walrasian general equilibrium approach and Marshall's partial equilibrium, based on the different methodologies that these two economists endorsed. Marshall, and later Friedman defended the partial approach based on the limitations of human knowledge and reasoning capacity: "Man's powers are limited: almost every one of nature's riddles is complex. He breaks it up, studies one bit at a time, and at last combines his partial solutions with a supreme effort of his whole small strength into some sort of an attempt at a solution of the whole riddle" (Marshall in Friedman, 1949, p. 469). Walras, by contrast, attempted to give a formal account of the existence of a general equilibrium thinking that this comprehensive knowledge was key. Therefore, it could be said that Csaba is simply reaffirming the relevance of the debate and trying to make the case for a kind of holistic, Walrasian general equilibrium approach, which includes institutional factors.

Unfortunately, Csaba does not say much more about what the holistic approach he endorses involves, so it is difficult to judge how strong is the contrast he wants to make with the partial analysis he criticises. But, if one takes his criticism literally, he seems to be suggesting that it is not possible to reliably model aspects of the economy if the entire economy - its structure - is not modelled first. There are at least two problems with this view. First, it presupposes that the entire structure of the economy, including the legal and institutional aspects of the system paradigm, is known and can be known. This would involve knowing the causal factors "which sets its workings in motion", the strength of the effects that each of these causal factors has, the way in which they interact with other factors, how they might change when structural changes take place, etc. This kind of knowledge, however, is at best, quite hard to come by in the social sciences. John Stuart Mill, in his A System of Logic, already recognised the difficulty of knowing all the causal factors of a phenomenon and how their conjunction might work in political economy. He thus thought that theory could only make claims of causal tendencies or of regularities that would hold if dis- 
turbing factors were absent, instead of claims of causal laws or universal regularities (Mill, 1884). It could be that Csaba means that, in the system paradigm he defends, only the relevant factors or those that are known to be important need to be included. While this is perhaps less demanding, it is not necessarily more feasible. Furthermore, since some aspects necessarily have to be left out, the question becomes a matter of degree rather than of totally different approaches. Neglecting this fact leads to the second problem of Csaba's view, namely that it ignores the importance of purposes in determining the aspects that ought to be included in the analysis. The different purposes that are pursued in the social sciences as well as the different enquiries demand different methods and consideration of the different elements that are relevant for the question being answered.

I sympathise with Csaba's plea for a more comprehensive approach that is closer to that of political economy: one that considers the legal, social, historical, and institutional underpinnings of economic reality. But the cognitive limitations that Marshall referred to, as well as the complexity and changing nature of social phenomena cannot be ignored. Once these constraints are acknowledged, one can see that the Marshallian and Walrasian approaches each give primacy to different considerations, none of which is obviously more important than the other: the former is cautious the latter ambitious. It thus seems to me that a more productive way to address this debate is to focus on what the right balance might be between these two considerations for different kinds of questions rather than to a priori decide which one is the best.

The second aspect I shall address is the role of values in scientific practice. In his paper, Csaba suggests that one of the remarkable features of Kornai's approach to the discipline is his "non-ideological and non-normative approach". Csaba emphasises the descriptive character of Kornai's work, especially his ability to meticulously describe the workings - or lack thereof - of the soviet economy, trying to portray Kornai's work as descriptive and objective: "Economics no longer served any ideological purpose - of justifying or undermining communist ideas and party rule - but was a means to comprehend empirical realities" (p. 35). Csaba suggests that there is a difference between Kornai and other commentators whose analysis was heavily influenced by their ideology. This was a feature that Kornai shared with the mainstream and that therefore made him deserving of the mainstream's appreciation. Anti-Equilibrium, for instance, Csaba suggests, described the economy "in technical terms, without historic or ideological prejudices or axioms, quite in line with Samuelson and Arrow" (p. 38) Still, Csaba concedes that there are some books of Kornai that are 'radical'. When he discusses The Socialist System, in which Kornai offered an "autopsy" of the socialist system after its collapse, Csaba acknowledges that in this book Kornai returned to the radicalism of his first book, suggesting that it was not a fully dispassionate analysis: "If seen through the contemporary standards of academic purism this is clearly a step back from the meticulous attention to 
the detailed and the impartial, formal analysis of politically neutral economic events, forms, interactions and institutions, as practised in the previous three books..." (p. 44). Yet, Csaba also adds that Kornai's return to radicalism is justified given the need to confront soviet reality in all its complexity and that it was somehow inevitable to fall into such radicalism after the soviet collapse: "It was impossible to withstand the liberating air of the new era. Also, it was time to give up the practice of being content with half-truth, with the need to employ self-censorship in order to get our ideas in print..." (p. 44). To be fair, Csaba is ambiguous about what this radicalism means. Sometimes he strikes a difference between radicalism and impartiality, whereas with respect to the first book, Overcentralisation, he calls it radical but also "a descriptive, analytical piece, rather than anything speculative-normative" (p. 35). Still, I think Csaba seems to be suggesting that being partial is both a decision - as Kornai presumably decided when he 'gave up the practice of being content with halftruth' after the demise of the soviet system - and something that can be read or identified - as Csaba does with Kornai's work - as impartial or not. Both tasks seem to me much more difficult than Csaba makes them look.

The aim for objectivity is certainly one of science's most distinguished features and a virtue in those practitioners who strive for it. But science is not value-free. And, it is an open question whether it is desirable to pretend otherwise. Economists and scientists in general necessarily make value judgements from the very moment in which they decide to investigate a particular phenomenon - and not another. Likewise, the choice of the methods with which a question is addressed is a matter of judgement. A good example is the current debate in development economics between the 'randomistas', who think that their method of identifying causal relations is necessary and sufficient to solve the problem of poverty, and those who claim that prior theoretical knowledge is necessary for understanding how the economy works and to afterwards be able to carry out sound policy. These methodological choices often go hand in hand with other non-epistemic judgements such as the decision to experiment on human populations, or the idea that the intrinsic motivation of teachers in rural Udaipur, India can be easily traded-off for external monetary incentives if the evidence suggests that the latter decrease teacher absenteeism (see Banerjee \& Duflo, 2006). These are ethical and moral judgements. I do not want to suggest that they are good or bad, just that they are judgements after all, which are not purely epistemic and therefore cannot be seen as impartial or politically neutral, as Csaba seems to suggest. Given that these kinds of judgement are ubiquitous, particularly in the social sciences, it is an open question whether economists and other social scientists should pretend to be neutral, or if perhaps another way to deal with value judgements in science is to be explicit about all our ideological commitments.

Let me conclude with a remark about the critique that Csaba makes of the economics 'mainstream'. As mentioned above, Csaba's main concern is that 
Kornai's work has not been sufficiently appreciated. I wish Csaba had employed a different strategy and argued how precisely the mainstream is at a loss for ignoring Kornai's intellectual contributions. In this way, he would have demonstrated the qualities of Kornai and his critique of the mainstream would have been positive; by highlighting that which Kornai's work has that the mainstream does not. It is unfortunate that Csaba chose instead to offer negative and standard criticism such as that the mainstream, interested only in the aesthetic qualities of mathematical beauty, ignored Kornai for having "remained much too concerned with realities, especially in the Communist and Post-Communist world" (p. 49, emphasis in the original). He also chose to suggest that the game is somehow rigged: he makes unfounded and bold claims such as that commentators regard Kornai's work "a perfect fit for a classical Nobel Prize" but that he did not receive it because the "Riksbank is a forum for political fights and fights of tastes" (p. 43) or that Kornai's Socialist System "led to the exclusion of its author from the temple of the mainstream and 'relegating' him back to institutionalism..." (p. 43). Economists have seldom paid attention to this kind of criticism and I seriously doubt that they will start to do so. Csaba has thus regrettably clouded the tribute to his intellectual hero with a protest that will very likely remain unheard.

\section{References}

Banerjee, A., \& Duflo, E. (2006). Addressing absence. Journal of Economic Perspectives, 20(1), 117-132. https://doi.org/10.1257/089533006776526139

Friedman, M. (1949). The Marshallian demand curve. Journal of Political Economy, 57(6), 463-495.

Kornai, J. (1998). The system paradigm. Retrieved from https://deepblue.lib.umich.edu/ bitstream/handle/2027.42/39662/wp278.pdf

Mill, J. S. (1884). A system of logic, ratiocinative and inductive: being a connected view of the principles of evidence and the methods of scientific investigation, $8^{\text {th }}$ edition. New York: Harper \& Brothers. 